Viscoelastic Postseismic Rebound to Strike-Slip Earthquakes in Regions of Oblique Plate Convergence, Steven C. Cohen, Geodynamics Branch, NASA Goddard Space Flight Center, Greenbelt, MD 20771, 301-614-6466; scohen@carnoustie.gsfc.nasa.

Popular Summary

When an earthquake occurs, stress is transferred from the brittle, elastic upper crust to the more ductile, i.e. viscoelastic, lower crust and asthenosphere. These ductile regions flow in response to the changes in the ambient stress level and this flow induces postseismic ("after earthquake") surface deformations. The surface deformations are detectable by GPS and other space geodetic techniques so the measurement of postseismic rebound gives insight into the rheology and geometry of subsurface geological features.

In introductory courses on plate tectonics one is often taught that there are three types of plate boundaries: convergent ones where the plates approach one another, divergent ones, where they pull apart, and transcurrent ones where they slide past one another. In fact, plate boundaries are often more complex than these simple end member cases. One common type of plate boundary is the obliquely convergent subduction zone. Here an oceanic plate, subducts, or slides under a continental plate at a deep sea trench. In addition the continental plate slides laterally over the subducting plate. Instead of the relative motion being perpendicular to the trench, as it is in the case of the purely convergent boundary, the relative motion is at an oblique angle to the trench.

One of the consequences of oblique convergence is that earthquakes occur not only on the boundary between the converging plates but also along faults lying in the crust of the overriding continental plate. Many of these continental seismic zones exhibit lateral motion or strike-slip motion that takes up the trench parallel component of the relative plate motion. The viscoelastic rebound to earthquakes on these crustal faults is different from viscoelastic rebound to strike-slip earthquakes in regions where the relative motion is purely lateral because the underlying ductile material is in underlain by the subducting elastic oceanic plate. This more complex geometry alters both the pattern of ductile flow at depth and the surface deformations. Calculations presented in the paper show that the rates of postseismic movement can differ by $1-2 \mathrm{~cm} / \mathrm{yr}$ shortly after a moderate to large earthquake. Thus we find that although a more complicated model is required to interpret postseismic rebound observations in oblique convergence zones, the measurements have the potential to reveal important information about subsurface tectonic structures.

This paper is being submitted to the Bulletin of the Seismological Society of America 


\title{
Viscoelastic Postseismic Rebound to Strike-Slip Earthquakes in Regions of Oblique Plate Convergence
}

\author{
Steven C. Cohen \\ Geodynamics Branch, NASA Goddard Space Flight Center, Greenbelt, MD 20771 \\ 301-614-6466; scohen@carnoustie.gsfc.nasa.gov
}

\begin{abstract}
According to the slip partitioning concept, the trench parallel component of relative plate motion in regions of oblique convergence is accommodated by strike-slip faulting in the overriding continental lithosphere. The pattern of postseismic surface deformation due to viscoelastic flow in the lower crust and asthenosphere following a major earthquake on such a fault is modified from that predicted from the conventual elastic layer over viscoelastic halfspace model by the presence of the subducting slab. The predicted effects, such as a partial suppression of the postseismic velocities by $1 \mathrm{~cm} / \mathrm{yr}$ or more immediately following a moderate to great earthquake, are potentially detectable using contemporary geodetic techniques.

\section{Introduction}

Earthquakes transfer stress from the elastic, brittle upper crust to the more ductile lower crust and upper mantle. These deeper regions respond by flowing in response to the change in the deviatoric stress acting on the ductile material. The ductile flow results in time-dependent deformation not only at depth, but also at the surface of the earth. Thus postseismic deformations depends on both the rheology and geometry of the relevant tectonic features. The classical, two-dimensional, viscoelastic rebound model, as introduced by Nur and Mavko [1974], is shown for strike slip faulting in Fig 1 . In this model the fault, extending from an upper depth, $d_{l}$, to a lower depth, $d_{2}$, and is embedded in an elastic layer of thickness, $H$, characterized by a shear rigidity, $\mu_{l}$. The elas- 
tic layer is underlain by a viscoelastic halfspace characterized by its rigidity, $\mu_{2}$, and viscosity, $\eta$.

Taking a coordinate system with the 1 axis aligned with fault strike, the 3 axis pointing vertical, and the 2 axis forming the perpendicular, a particularly simple closed-form expression for the displacement, $u_{l}$, is obtained when $\mu_{l}=\mu_{2}, d_{l}=0$, and $d_{2}=D$ [Cohen, 1999 and references therein], viz:

$$
\frac{u_{1}}{u_{o}}=\frac{1}{2}-\frac{1}{\pi} \operatorname{atan} \frac{x_{2}}{D}+\sum_{n=1}^{\infty} V_{v e}\left(x_{2}, t, n\right)
$$

where $V_{v e}=G(x, n) T(t, n)$ and

$$
\begin{gathered}
G(x, n)=\frac{1}{\pi} \operatorname{atan}\left[\frac{2 \frac{x_{2}}{D}}{\left(2 n \frac{H}{D}\right)^{2}-1+\left(\frac{x_{2}}{D}\right)^{2}}\right], \\
T(t, n)=\frac{1}{(n-1) !} \int_{0}^{\frac{t}{2 \tau}} r^{n-1} \exp (-r) d r .
\end{gathered}
$$

Note that $T(t, 1)=1-\exp (-t / 2 \tau)$; the subsequent terms can be derived from the recursion relation: $T(t, n+1)=T(t, n)-r^{n} \exp (-r) / n !$ where $r=t / 2 \tau$ and $\tau=\eta / \mu$ is the Maxwell time of the viscoelastic material. Velocity can be derived by time differentiating the displacement equation and shear strain by taking the derivative with respect to $x_{2}$.

There have been numerous analytical and numerical extensions of the preceding formulation that take into account more detailed horizontal layering, lateral variations in elastic and viscoelastic parameters, and non-vertical faulting. Here we wish to focus attention on a particularly important issue which has received little if any attention in the past: the effect of having a subducting 
slab lying under the crustal fault. This is a common occurrence in regions of oblique convergence where the trench parallel component of the relative plate motion is often accommodated by strikeslip faulting in the overriding continental plate [Fitch, 1972, Walcott, 1978, McCaffery, 1992]. A good example can be found in the Wellington region of the North Island of New Zealand [e.g. Beanland, 1995]. Here, i.e. at the Hikurangi trough off the east coast of the North Island, the Pacific Plate subducts beneath the Australian Plate. The obliquity increases from north to south and is more than 45 degrees at the latitude of Wellington. Much of the trench parallel motion is taken up on the major right lateral faults of the North Island Shear Belt (NISB), notably the Wairarapa and Wellington Faults, located some $140-170 \mathrm{~km}$ inboard of the trench. Both of these right lateral faults manifest long term slip rates on the order of $1 \mathrm{~cm} / \mathrm{yr}$ and both are known to be seismically active with the Wairarapa Fault rupturing in a magnitude $8+$ event in 1855 . Thus, the possibility of postseismic deformation, particularly viscoelastic rebound, following a strike-slip earthquake here, as in other zones of oblique convergence, merits consideration. In this paper I report the results of numerical experiments performed to elucidate the differences between the viscoelastic postseismic rebound patterns predicted by the simple layer over halfspace model (layered model) and those predicted by a model that takes the subducting plate geometry into account (plate model). I take the occurrence of strike-slip faulting at oblique convergence zones as an empirical fact. By contrast, Braun and Beaumont [1995] have previously reported the results of an investigation into how strain partitioning arises in elastic-brittle material driven by basal stresses.

\section{Model, Results, and Discussion}

Since we are dealing with a convergent plate boundary, it is convenient to refer to the overthrust block as the continental plate and the underthrust block as the oceanic plate. As in Fig. 1, the fault 
lies at $x=200 \mathrm{~km}$ and the surface of the overthrust (underthrust) block is at $\mathrm{x}<0(x>0)$. I will occasionally refer to the region where $\mathrm{x}<0(\mathrm{x}>0)$ as the continental (oceanic) plate even when alluding to the layered model, where no subduction occurs. The solutions for the layered model were obtained using the analytical expressions while the solutions for the plate model were obtained with finite element techniques. I verified that the finite element code reproduced the analytical results for the layered geometry. The velocities obtained for typical calculations are shown in Fig. 2. In the layered case, the elastic layer was $20 \mathrm{~km}$ thick and the fault penetrated through the entire elastic layer. In the plate case, both the continental and oceanic plates had a thickness of $20 \mathrm{~km}$. The fault penetrates through the entire continental plate. The dip angle of the subducting plate increases with increasing distance from the plate boundary in a manner consistent with typical subduction zone geometries. As a practical matter in generating the finite element grid, I found it convenient to let the subducting plate thin somewhat with depth from its unsubducted thickness of $20 \mathrm{~km}$ (see Fig. 2), but this variation in thickness does not affect the conclusions presented herein. The Maxwell relaxation time, $\tau$, was chosen to be 3.2 years. Fig. 2 a shows the surface velocity one-half year after an earthquake. The deformation both landward and seaward of the strike-slip fault is reduced in the plate model as compared to the layered model. The difference in the predicted velocities derived from the models is about $1-2 \mathrm{~cm} / \mathrm{yr}$ per meter of coseismic slip at a distance of about one fault depth from the fault. This is well within the detection capability of modern geodetic techniques. Thus the effects of the plate geometry should be discernible for viscoelastic rebound to great, large, and even some moderate magnitude earthquakes. The physical basis for some of the differences in model behavior is easy to understand. Relative to the layered model, deformation is reduced in the plate model on the trenchward side of the fault because the coseismic stress change is partially supported by both the continental and underlying oceanic 
plates. Thus the effective elastic thickness is greater than in the layered model. In fact, Fig $2 b$ shows a comparison between the postseismic velocities from the plate model and a layered model in which the thickness of the elastic layer in the layered model has been doubled to $40 \mathrm{~km}$ with no change in the faulting depth of $20 \mathrm{~km}$. Notice the similarity in the velocities on the oceanic side of the fault. Returning to Fig. 2a, deformation is reduced on the continental side of the fault because the viscoelastic material is confined to a wedge, bound on the lower side by the top of the subducting plate. Note, however, that the fastest moving points are farther from the fault in the plate model than in the layered model. Fig. 3a shows the cumulative postseismic displacement after 200 yrs by which time the displacements have diffused into the far field far more successfully in the layered model. At $100 \mathrm{~km}$ from the fault, the displacement in the layered model is more than $80 \%$ of the coseismic slip, whereas in the plate model it is only about $50 \%$ or less.

In Figs. 2a and 3a the thicknesses of the continental plate and oceanic plates were approximately equal. I now examine in more detail the effect of varying the elastic plate thickness by looking at end members where the elastic thickness of one of the two plates is infinite, but the fault depth remains $20 \mathrm{~km}$. The results are shown in Fig. 3b. When the oceanic plate is thick, the postseismic displacements at the surface are suppressed on both the oceanic plate and the oceanward side of the continental plate. However, displacements on the continental side of the strike-slip fault, may be enhanced over that predicted from a layered halfspace model The enhancement in the near field is evidenced in the figure. Similarly, if the continental plate is made very thick, deformation on the continental side of the strike-slip fault is suppressed and deformation on the oceanward side of the continental plate may be enhanced or suppressed relative to the layered model depending on the distance from the fault and the time elapsed since the earthquake. Motion at the surface of the oceanic plate may also be reduced compared to the layered model. 
Many of the strike-slip faults that occur in subduction zones are not vertical structures, but, I do not consider this detail in the present paper for there is no simple solution comparable to equation (1) for non-vertical geometries. However, I do speculate that another difference between strikeslip faults in obliquely convergent and transcurrent zones, is that the former may extend to greater depths. Darby and Beanland (1992) fit the coseismic vertical defamation data (mostly beach terrace heights) from the 1855 Wairarapa earthquake with a listric fault model in which slip extends to a depth of $40 \mathrm{~km}$, much deeper than the slip in, for example, earthquakes along the transcurrent San Andreas Fault system. For the slip partitioning model to work in the sense of accommodating all the trench parallel motion on a strike-slip fault, the slip must extend to the depth at which the megathrust is locked. For typical subduction zones, this depth is $40 \pm 5 \mathrm{~km}$ [Tichelaaar and Ruff, 1993]. However, it is not necessary that the slip at all depths be coseimic. These considerations are relevant to the present paper in that a fault depth of $20 \mathrm{~km}$ that was used for the illustrative calculation is slightly deep for strike-slip faulting at transcurrent plate boundaries, but is representative or even a bit shallow for the similar faulting at obliquely convergence boundaries.

\section{Summary}

Qualitatively there are many similarities between viscoelastic postseismic rebound to strike-slip faulting in transcurrent and obliquely convergent environments. In both cases the sense of direction of the horizontal coseismic and postseismic motions are the same; although, this general behavior will be somewhat modified if the oceanic and continental plates have substantially different elastic thicknesses resulting in a horizontal variation in the depth to the viscoelastic material. Similarly, in both cases the displacements diffuse outward with time from the fault region into the plate interior. However, the details of the temporal and spatial pattern of postseismic horizontal deformation are different, and well within the detection capability of contemporary geo- 
detic measurements for rebound from moderate to great earthquakes. Thus, the interpretation of postseismic rebound observations following strike-slip earthquakes in convergent zones is likely to require the use of numerical models that are not quite as handy as the closed-form expression for a layered rheology. However, properly interpreted, these geodetic measurements will have the potential to give additional insight into the geometry of the subducting slab and into possible differences between strike-slip faulting at different types of plate boundaries.

Acknowledgments: I am indebted to Desmond Darby for an ongoing dialogue about New Zealand tectonics, for making me aware of the Wellington region GPS data, and for inviting me to visit the Institute of Geological and Nuclear Sciences where I first became interested in problems associated with slip partitioning. I am also indebted to John Beavan for sharing with me his interpretation of the GPS observations and for his helpful comments on my research. The finite element code, TECTON, developed by Jay Melosh and colleagues, was used to perform some of the calculations reported in this paper. This research was carried out under the auspices and with the financial support of NASA's Solid Earth and Natural Hazards Program. 


\section{REFERENCES}

Beanland, S., The North Island Dextral Fault belt, Hikurangi subduction margin, New Zealand, Victoria, University (Ph.D. thesis), 1995.

Braun, J., and C. Beaumont, Three-dimensional numerical experiments of strain partitioning at oblique plate boundaries: Implications for contrasting tectonic styles in the southern Coast Ranges, California and central South Island, New Zealand, J. Geophys. Res., 100, 18059-18074, 1995.

Cohen, S.C., Numerical models of crustal deformation in seismic zones, Advances in Geophysics, $41,133-231,1999$.

Darby, D.J., and S. Beanland, Possible source models for the 1855 Wairarapa earthquake, New Zealand, J. Geophys. Res, 97, 12375-12389, 1992.

Fitch, T.J., Plate convergence, transcurrent faults and internal deformation adjacent to southeast Asia and the western Pacific, J. Geophys. Res., 77, 4432-4460, 1972.

McCaffery, R., Oblique plate convergence, slip vectors, and forearc deformation, J. Geophys. Res., 97, 8905-8915, 1992.

Nur, A., and G. Mavko, Postseismic viscoelastic rebound, Science, 183, 204-206, 1974.

Tichelaar, B., and L. Ruff, Depth of seismic coupling along subduction zones, J. Geophys. Res., 98, 2017-2037, 1993.

Walcott, R.I., Geodetic strains and large earthquakes in the Axial Tectonic Belt of North Island, New Zealand, J. Geophys. Res., 83, 4419-4429, 1978. 


\section{FIGURE CAPTIONS:}

Figure 1: Fault models. The top panel shows the layered model applicable to transcurrent plate boundaries and for which the postseismic displacements have been calculated using equation (1). The bottom panel shows the plate model applicable to oblique convergence zones and for which the displacements are calculated using finite element techniques.

Figure 2: Velocity at $t=0.5$ yrs versus distance from the fault for a fault slip of $1 \mathrm{~m}$ and a Maxwell time of 3.2 years. The strike slip fault is located at $x=-200 \mathrm{~km}$. For the layered halfspace, $H=D=20 \mathrm{~km}$. (a) For the plate model, $D=20 \mathrm{~km}$, the dip of the subducting plate is $5.7^{\circ}$ from the surface to a depth (top of the slab) of $20 \mathrm{~km}, 11.3^{\circ}$ from 20 to $40 \mathrm{~km}, 26.6^{\circ}$ from 40 to $90 \mathrm{~km}$, and $45^{\circ}$ from 90 to $190 \mathrm{~km}$ and the slab is 20 thick along a vertical path. (b) For the layered halfspace $H=40 \mathrm{~km}, D=20 \mathrm{~km}$. The plate model is the same as in (a)

Figure 3: (a) Cumulative postseismic displacement after 200 yrs. (a) For the plate and layered models described in the text and the caption of Fig. 2a. (b) For the plate and layered models as in (a) and for very thick oceanic and continental plates. 


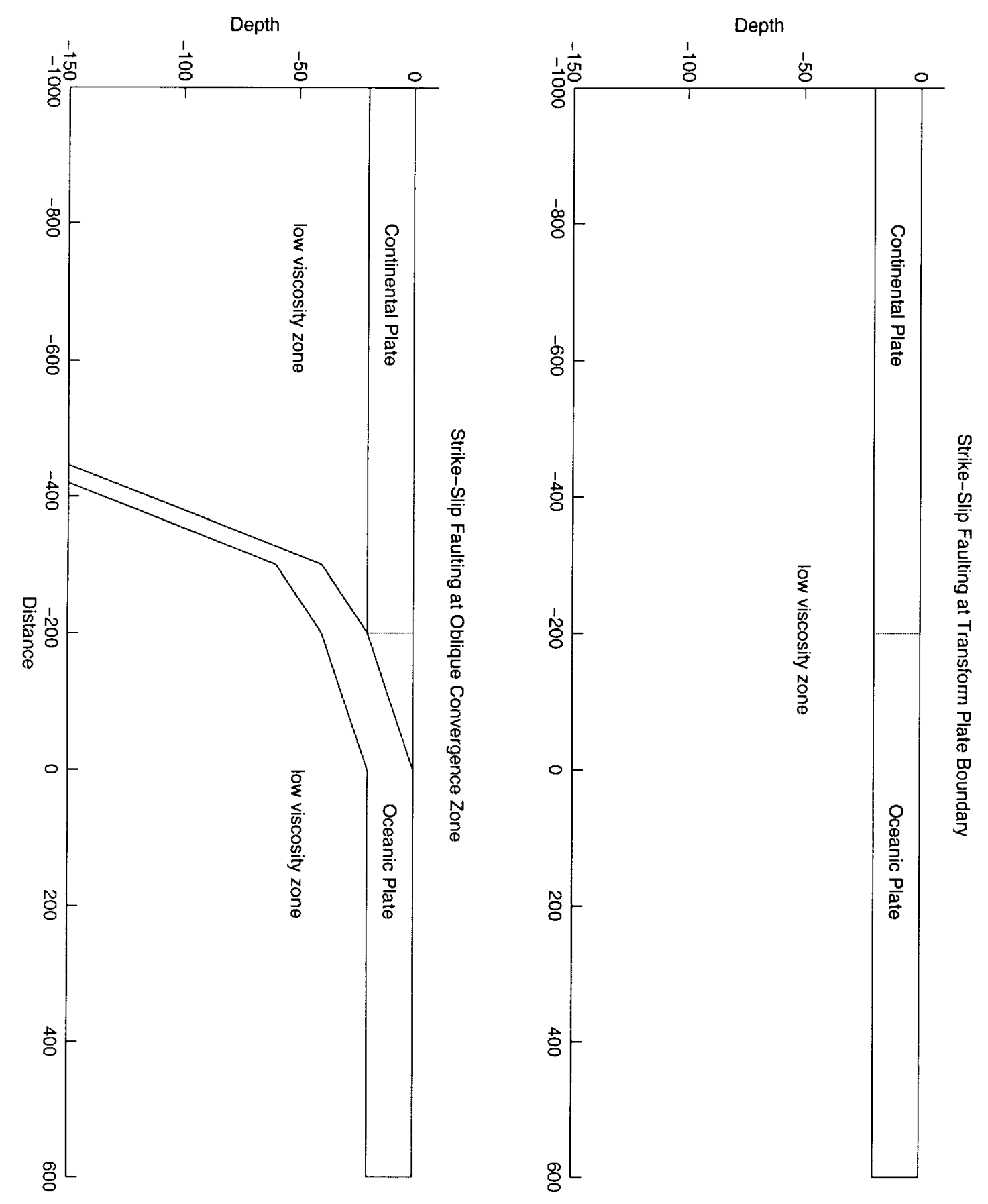

Figure 1 
a.

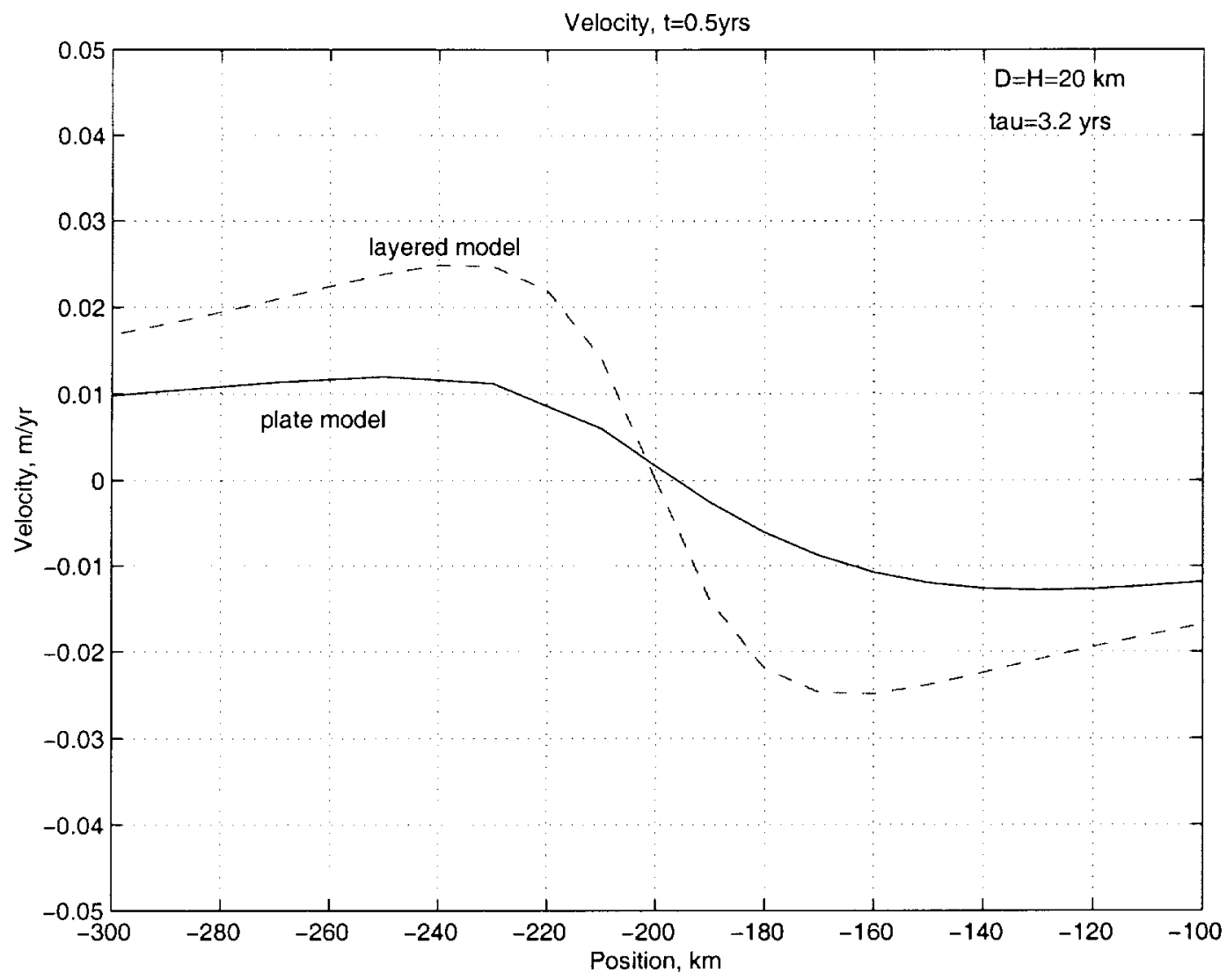

b.

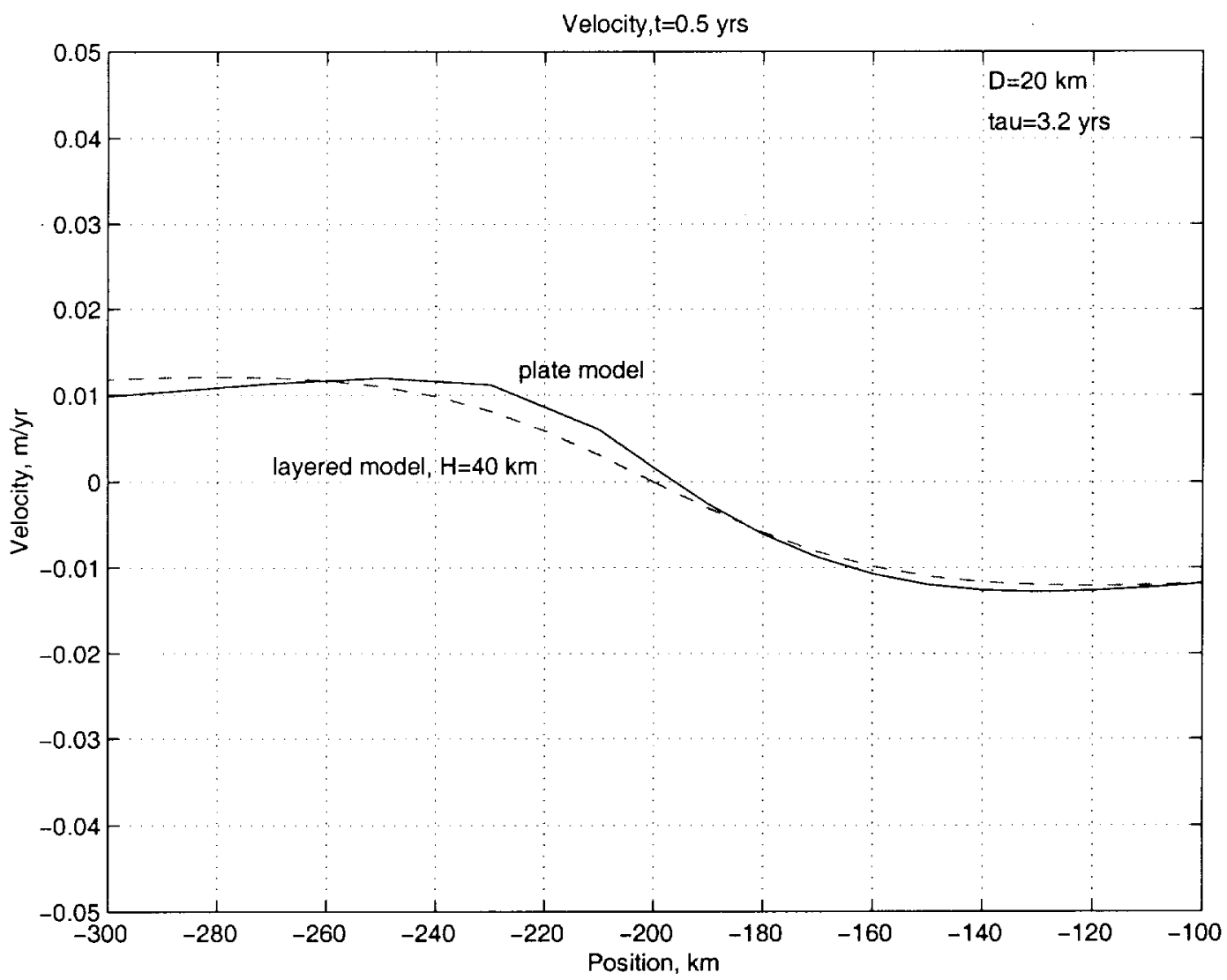

Figure 2 
a/

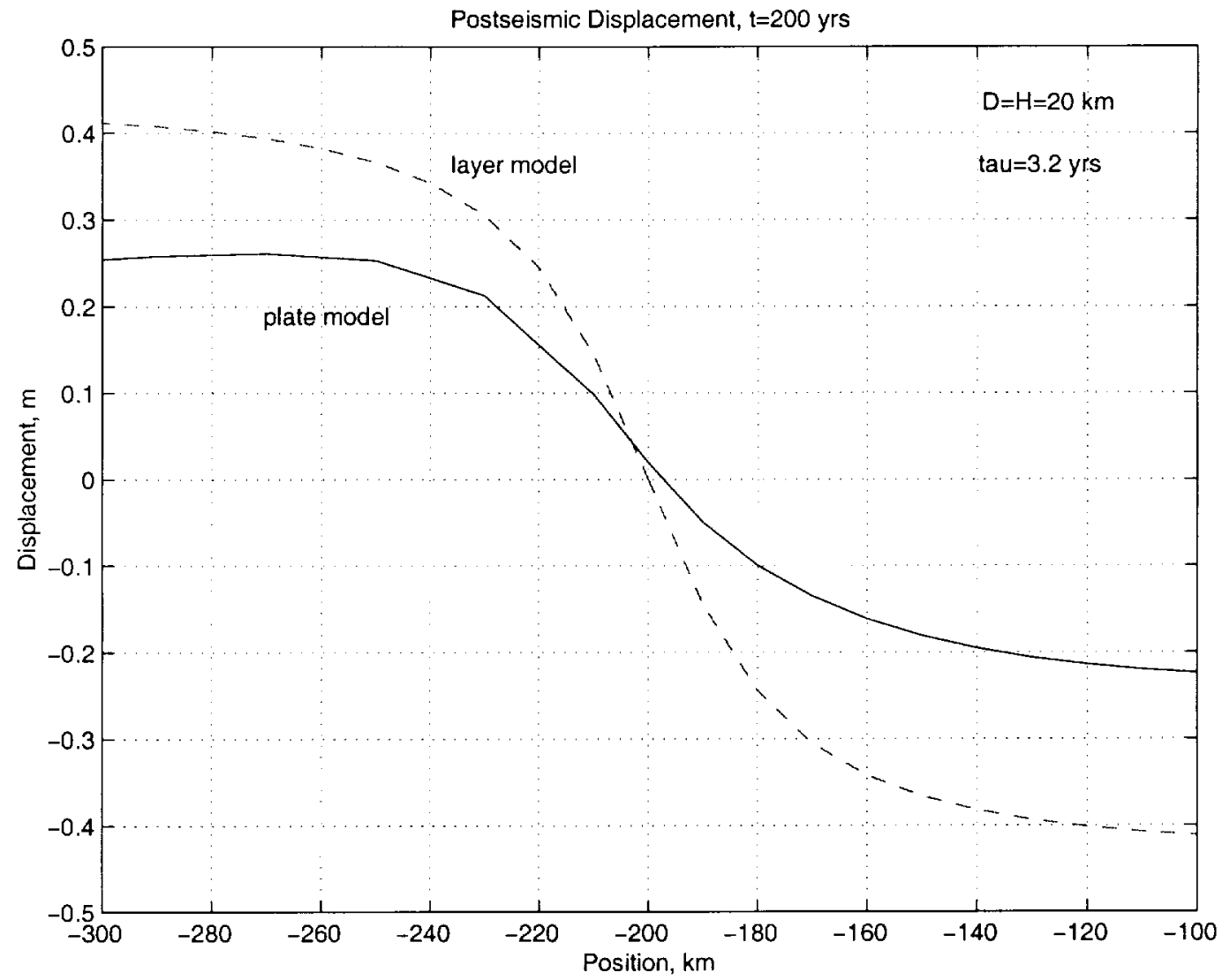

b.

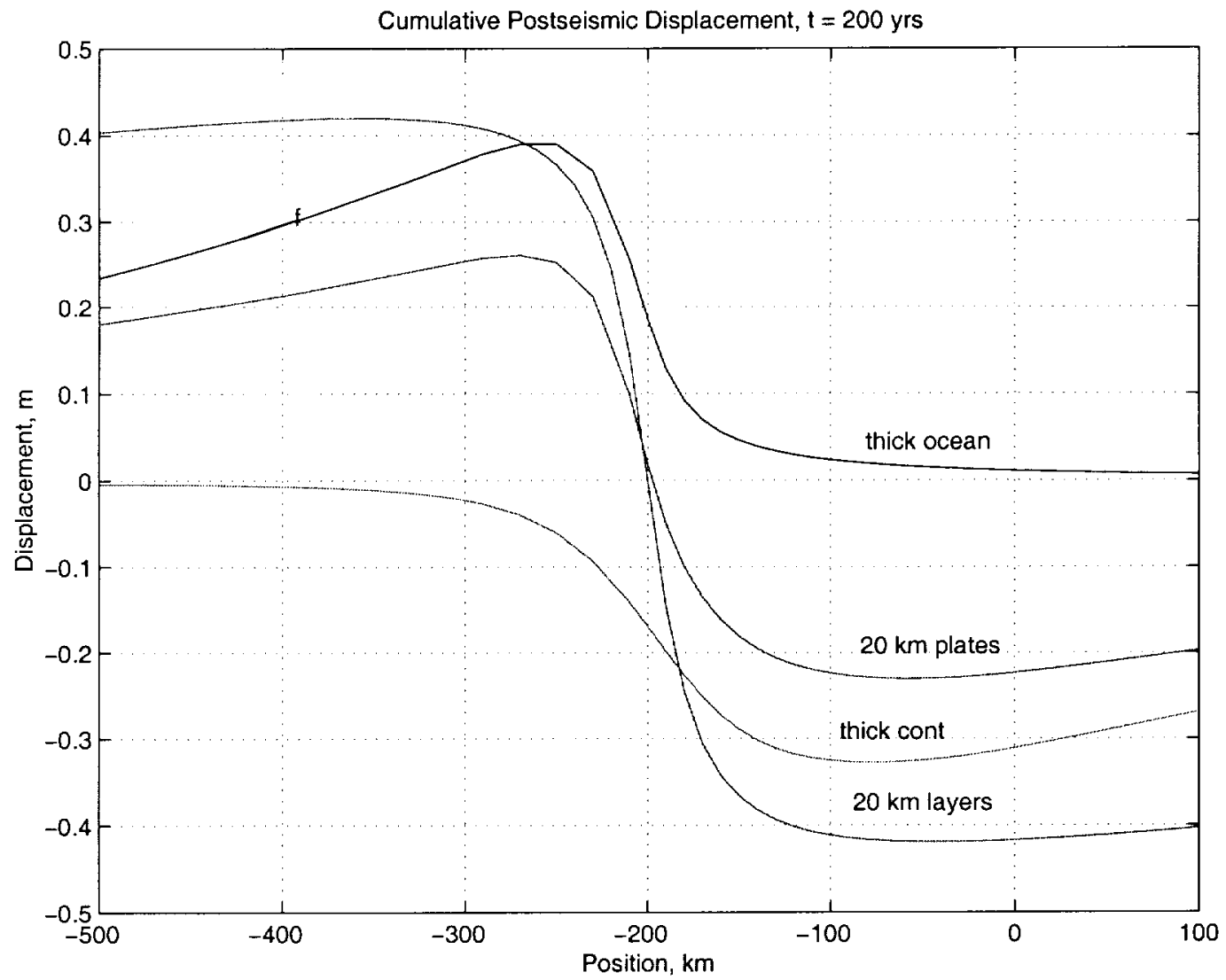

Figure 3 